\title{
BMJ Open Needs of LMIC-based tobacco control advocates to counter tobacco industry policy interference: insights from semi- structured interviews
}

\author{
Britta Katharina Matthes (D) , ${ }^{1}$ Lindsay Robertson, ${ }^{1,2}$ Anna B Gilmore ${ }^{1}$
}

To cite: Matthes BK,

Robertson L, Gilmore AB. Needs of LMIC-based tobacco control advocates to counter tobacco industry policy interference: insights from semi-structured interviews. BMJ Open 2020;10:e044710. doi:10.1136/ bmjopen-2020-044710

- Prepublication history for this paper is available online. To view these files, please visit the journal online (http://dx.doi. org/10.1136/bmjopen-2020044710).

Received 14 September 2020 Revised 03 October 2020 Accepted 06 October 2020

Check for updates

(C) Author(s) (or their employer(s)) 2020. Re-use permitted under CC BY-NC. No commercial re-use. See rights and permissions. Published by BMJ.

${ }^{1}$ Department for Health, University of Bath, Bath, UK ${ }^{2}$ Department of Preventive and Social Medicine, University of Otago, Dunedin, New Zealand

Correspondence to Dr Britta Katharina Matthes; bkm28@bath.ac.uk

\section{ABSTRACT}

Introduction Advocacy is vital for advancing tobacco control and there has been considerable investment in this area. While much is known about tobacco industry interference (TII), there is little research on advocates' efforts in countering TII and what they need to succeed. We sought to examine this and focused on low- and middle-income countries (LMICs) where adoption and implementation of the Framework Convention on Tobacco Control (FCTC) tend to remain slower and weaker. Method We interviewed 22 advocates from eight LMICs with recent progress in a tobacco control policy. We explored participants' experiences in countering TII, including the activities they undertake, challenges they encounter and how their efforts could be enhanced. We used Qualitative Description to analyse transcripts and validated findings through participant feedback.

Results We identified four main areas of countering activities: (1) generating and compiling data and evidence, (2) accessing policymakers and restricting industry access (3) working with media and (4) engaging in a national coalition. Each area was linked to challenges, including (1) lack of data, (2) no/weak implementation of FCTC Article 5.3, (3) industry ties with media professionals and (4) advocates' limited capacity. To address these challenges, participants suggested initiatives, including access to country-specific data, building advocates skills in compiling and using such data in research and monitoring, and in coalition development; others aiming at training journalists to question and investigate TII; and finally, diverse interventions intended to advance a wholeof-government approach to tobacco control. Structural changes to tobacco control funding and coordination were suggested to facilitate the proposed measures.

Conclusion This research highlights that following years of investment in tobacco control in LMICs, there is growing confidence in addressing TII. We identify straightforward initiatives that could strengthen such efforts. This research also underscores that more structural changes to enhance tobacco control capacity building should be considered.

\section{INTRODUCTION}

The importance of tobacco control advocacy is enshrined in the WHO Framework Convention on Tobacco Control (FCTC), the first global public health treaty. Its guiding
Strengths and limitations of this study

- A key strength of this study is that it includes the voices from advocates in eight countries (in four WHO regions and from the three low- and middleincome groups).

- While all countries included experienced recent advances in tobacco control, our sample was drawn from countries that had enacted varying policies and regulations, meaning we identified advocates' common needs across different policy contexts.

- A limitation of the study is that the views expressed are not necessarily generalisable to the broader population of tobacco control advocates.

- Another limitation is that we only included participants who were fluent in English which limited the pool of potential participants.

principles state that "the participation of civil society is essential in achieving the objective of the Convention and its protocols'. ${ }^{1}$ In line with this, major public health organisations, including intergovernmental agencies, nongovernmental organisations and funding agencies have been supporting tobacco control advocates worldwide. Given the evidence that tobacco industry interference (TII) is a major barrier to successful FCTC implementation, ${ }^{2}$ some of these initiatives focus on TII, including via published materials and training. ${ }^{3-5}$

Given that the adoption and implementation of the FCTC provisions tend to remain slower and weaker in lowmiddle-income countries (LMICs) than in high-income countries (HICs), ${ }^{6-8}$ finding ways to address TII effectively could lead to significant public health gains in LMICs. ${ }^{89}$

Impacts of initiatives such as the Bloomberg Initiative to Reduce Tobacco Use in LMICs have been documented, ${ }^{10}$ and some tobacco control capacity-building initiatives evaluated. ${ }^{11}{ }^{12}$ However, to our knowledge, there 
has been no work exploring whether there are gaps that would, if addressed, enable advocates to address TII better. Furthermore, while there is a substantial body of literature on TII, the majority is based on HICs. ${ }^{13-15}$ Few articles ${ }^{16-19}$ focus on countering interference and the role of advocates in this. There is a distinct lack of published research on what support advocates need to counter TII successfully.

To inform future efforts to address TII in LMICs more effectively, this study aims to enhance our understanding of LMIC-based advocates' experiences of countering TII and their unmet needs. We ask:

- In what activities do LMIC-based advocates engage when countering TII?

- What challenges arise when LMIC-based advocates engage in countering TII?

- How could advocates' activities be enhanced, challenges overcome and unmet needs addressed?

Addressing these questions will provide a critical reflection on existing efforts to support tobacco control advocates in countering TII in LMICs and would enable future initiatives to be (better) tailored to advocates' needs.

\section{METHODS}

This study took a qualitative approach ${ }^{20}$ based on semistructured interviews with LMIC-based tobacco control advocates which we analysed using Qualitative Description. $^{21} 22$

\section{Sampling and recruitment}

We purposely selected eight countries which had recently advanced or attempted to advance important tobacco control policies. The selected countries had adopted or consulted on health warning regulations (Bangladesh, India, Sri Lanka), comprehensive tobacco control policies including health warnings (Ethiopia, Uganda, Zambia), or significantly increased tobacco tax (Colombia, Ukraine) (see table 1). We sought to capture experiences from a diverse set of LMICs and thus the eight countries represent four of the six WHO regions and the three income-economy groups within LMICs.

Within these countries, we selected interviewees with sufficient experience of TII and attempts to address it. They were required to have at least three years of experience in national-level tobacco control advocacy, meaning that they have been working to advance tobacco control policy in their country. ${ }^{23}$ They also had to speak English. While this created limitations, it enabled us to avoid additional challenges associated with working with multiple interpreters. ${ }^{24}$ To ensure we recorded varying perspectives from each context, we sought to include two to four interviewees from more than one civil society organisation (CSO) in each country. CSOs are a broader category than non-governmental organisations (NGOs) and include, for example, charities, NGOs and professional bodies $^{25}$ and is therefore more appropriate for capturing the range of organisations involved in tobacco control.
We identified the first participants using our networks of tobacco control advocates and researchers, and subsequently used a snowballing approach. We invited potential participants via email with an information sheet.

\section{Data collection}

Informed by the existing peer-reviewed literature on TII, and particularly that on countering TII and advocates' role ${ }^{16-19}$ we developed the interview guide. It explored participants' experiences of countering TII and their views on what could facilitate CSOs' efforts in this regard in their country. It also probed examples of TII in the participant's country; those data form part of a separate study. The interview guide was revised through a series of author meetings and piloted with a tobacco control advocate and researcher who was, like most research participants, not a native speaker of English. All interviews were conducted in English, recorded with participants' permission, and subsequently transcribed.

\section{Data analysis}

We used Qualitative Description to analyse transcripts, ${ }^{21} 22$ facilitated by the use of NVivo V.12. With this approach, we aimed to summarise the content of the data in a way that allowed describing interviewees' perceptions and experiences, which lie at the study's heart. Key categories of analysis were derived from the research questions, reflected in the interview guide. Further subcategories were identified inductively. BKM conducted the coding and met regularly with $\mathrm{LR}$ and $\mathrm{ABG}$ to discuss coding and key findings. To validate findings, ${ }^{26}$ a summary was shared with 18 participants who had previously agreed to provide feedback, and eight (44\%) responded. They agreed with our findings and suggested some refinement which we took on board.

\section{Patient and public involvement \\ No patient involved.}

\section{RESULTS \\ Sample}

Between June and October 2019, we conducted 20 interviews with 22 participants from eight countries; two interviews had two participants. Five interviews took place in person and 15 remotely, using Microsoft Teams. The average length per interview was $90 \mathrm{~min}$. While all interviewees met the inclusion criteria, some held research or public sector positions in addition to being involved in tobacco control CSOs. Yet, all saw themselves primarily as advocates. The distribution of interviewees per country and type of policy change are indicated in table 2 .

Except for one country, at least two CSOs were included per country and the 22 participants came from 18 different organisations. The CSOs were diverse: some focused exclusively on tobacco control and others also engaged in other public health issues. Almost all received 


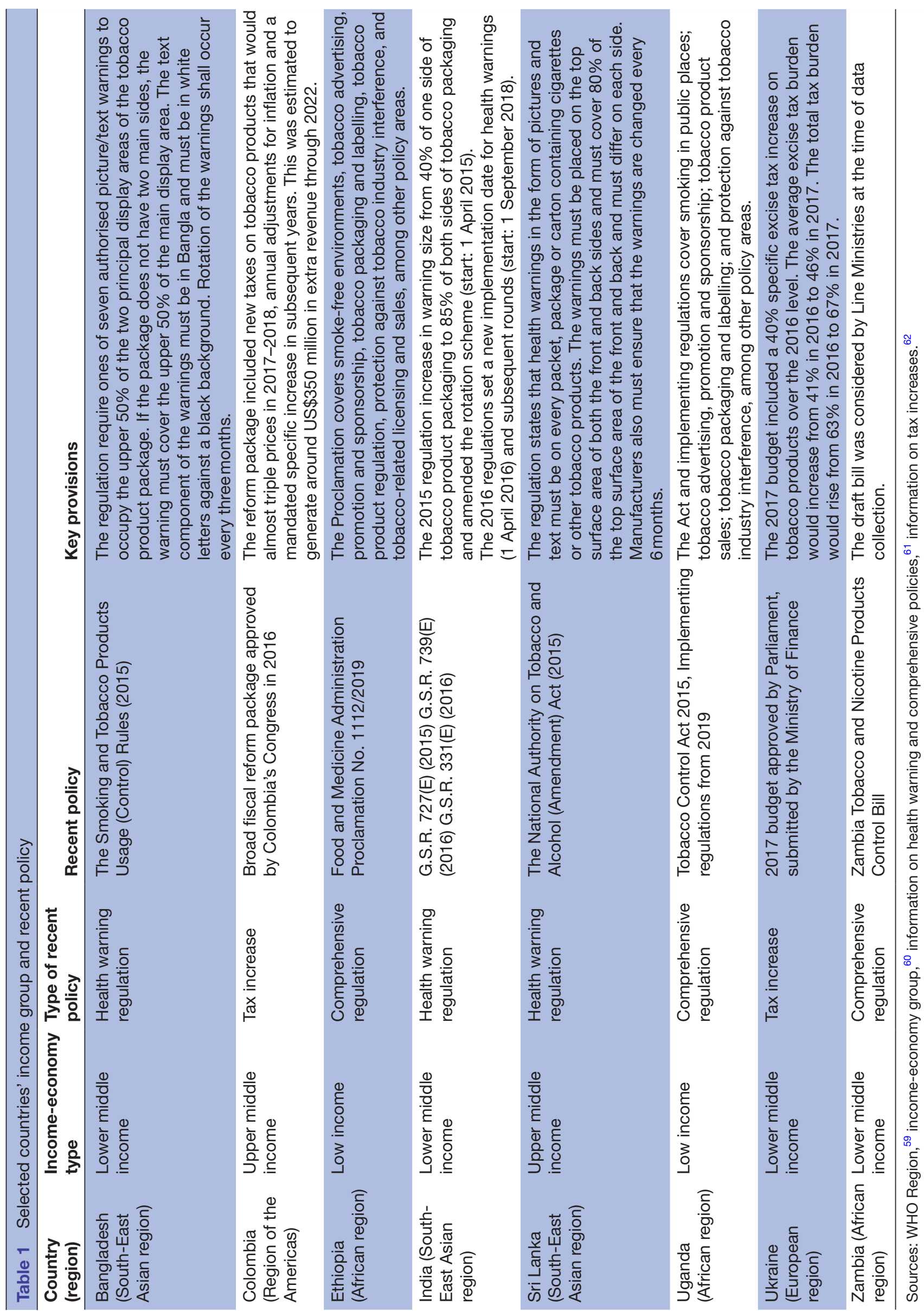


Table 2 Distribution and IDs of interviewees

\section{Recent tobacco control}

measures

Comprehensive bills/ laws

Health warning regulations

Tax increase
Countries (no of interviewees; interview medium)

Interviewee IDs

Ethiopia (3; online), Uganda (3, online), Zambia (4; in person)

Bangladesh (2; online), India (3; 1 online, 2 in person), Sri Lanka (2; online) P1-P22

Colombia (3; online), Ukraine (2; online) funding predominately from international tobacco control organisations.

\section{Countering activities: key areas and challenges encountered}

Countering TII was typically described as an integral part of a wider tobacco control advocacy strategy to advance specific pieces of regulation and thus generally planned. However, ad hoc responses were sometimes required to respond to specific developments. Activities to counter TII were usually influenced by the stage of the policy process, the specifics of policymaking within the given country, the type of tobacco control measure, and participants' expertise and capacity.

Nonetheless, participants consistently described seeking to predict, pre-empt and counter TII and identified four key areas of activity they regularly engaged in to achieve this. In each of these areas, they reported crucial and partly overlapping challenges.

\section{Generating and compiling data and evidence}

Data and evidence were perceived as vital to pre-empt or counter industry arguments; "as long as you press them [tobacco industry] using evidence,(...) they are defeated" (P12). Data were seen as useful for informing decision-makers directly and exposing tobacco industry misinformation in the media. A participant shared how a small-scale study on illicit trade conducted by his organisation, helped rebut industry claims during policy consultations:

It was like a game-changer during the public hearing meeting when we said it's not true. Our illicit trade is not [more significant figure] [as the tobacco industry claimed] it is only [less significant figure]. Then it changed the mentality of the parliamentarians. (P2)

Interviewees reported lacking up-to-date and reliable context-relevant data, especially on illicit trade, tobacco farming and cultivation, tobacco taxation, employment in the tobacco industry and on the environmental impact of tobacco. They emphasised the need for robust financial and economic data from sources independent of the tobacco industry. They found it difficult to obtain concrete evidence on TII, given that such activities were often hidden.

Beyond country-specific data, evidence detailing, for example, industry strategies and activities in similar countries, especially from the same region, was perceived as important. Other more generic information and resources such as factsheets, provided by the WHO or tobacco control organisations, were seen as useful. Still, they would often need to be translated to the local context, which required time and skill from advocates.

Interviewees also recognised limitations of evidence and data in countering TII: First, emotional narratives were said to matter as much as evidence since "having human stories is also very, very effective for policymakers and for $[\ldots]$ the public" (P15). Using such narratives would also mirror industry behaviour: "for the industry it's not about being precise, accurate, it's about bringing the emotion, making people believe the industry and not the advocates" (P18). Second, data and evidence need to reach the key people who need to act on them:

so much has been written about TII... among the tobacco control community, the knowledge is there. This knowledge is, however, absent in the people there to make decisions. (P22)

\section{Accessing policymakers and restricting tobacco industry access}

For countering TII, advocates saw establishing and sustaining direct access to policymakers as crucial. It enabled them to inform policymakers of tobacco industry conduct and misinformation, thereby, empowering them to make informed decisions.

However, participants agreed that access to policymakers, particularly those in Ministries of Finance, Trade and Agriculture and their respective parliamentary committees, was challenging. Informal links between the tobacco industry and policymakers from outside the health sector, who often believe the industry brings financial benefits, were a key hindrance. A participant recalled an informant telling them:

...the industry is in bed with [Ministry of] Finance, and with the committee in Parliament [...] they [policymakers] have completely blacklisted tobacco control; they don't come to any meetings, they don't want to be told anything, nothing. Because [...] the industry gives them lots of money. What is tobacco control going to offer? Nothing. That's where the challenge is. (P12)

In some countries, policymakers were reported to have direct conflicts of interest, including via the revolving door phenomenon or having a direct personal or family stake in a tobacco company. In a few countries, such a conflict of interest existed alongside a formal government commitment to tobacco control, for example, "the Prime 
Minister would like to make [country name] tobaccofree 2040 and at the same time, [the] government is the owner of the tobacco company in [country name]" (P8).

Interviewees also reported issues which enabled industry access to policymakers while constraining the tobacco control community's access. These included state agendas to promote tobacco as a cash crop, the establishment of a public body with this mandate and investor agreements between a tobacco company and a public entity.

While a formal implementation of FCTC Article 5.3 would help address this, policymakers outside the health sector were often said to be unaware of FCTC Article 5.3. Policies to domesticate this provision lacked in all eight countries. In some, the health ministry was not seen as sufficiently authoritative to introduce such a policy: "health ministry guys are feeling that "we are not such an authority to prepare a policy on Article 5.3 for the whole government'..." (P17). Limited state capacity was identified as a barrier to any future FCTC Article 5.3 policy implementation and enforcement.

\section{Working with media}

Working with the media was seen as key to obtaining and disseminating data and evidence, exposing and countering tobacco industry conduct, convincing policymakers and the public, and building public pressure on policymakers:

They [tobacco industry] wrote something in the newspaper, we go against, whenever we see any report, we respond to that with media, with publications and also, we use media to aware our community about their tactics, their influence and so on. (P20)

Key activities included building relationships with media executives, editors and journalists, organising press conferences and disseminating public statements. Where advocates were unable to carry out in-depth investigative work, they sought close collaboration with journalists who could "get [missing] information" (P22);

We regularly get some intelligence from them [journalists] on what has been happening regarding tobacco, in that particular ministry. That is one source of information. The main source, I would have to say. (P17)

One participant reported that the "[media] did play a very strong role in ensuring that the correct evidence was presented to the public [...] that way media had a strong contribution to getting the [policy]" (P15). In another case, the relationship with influential editors and reporters was crucial:

We knew all the content of the industry's opinion pieces before they came out on the newspaper. We had to inform the Chair of the [parliamentary] Committee and the Minister of Health that this thing is coming from the industry through the [third party]. We had a reporter investigating for us, who provided the content before the publication [...] that was really successful. (P1)

Some in-country CSOs also offered training on tobacco control and industry monitoring for journalists, which was perceived as strengthening the national tobacco control network.

However, working with the media was perceived as challenging as the tobacco industry sought to do the same. The industry built its relationships with the media, using incentives, including training for journalists. In all countries, interviewees saw their CSOs as unable to compete with the financial benefits the industry offered to media professionals. While participants from most countries reported that the tobacco industry concentrated on topic-specific media outlets popular among certain stakeholders, in other countries, it targeted widely read generic media outlets. A second challenge related to the above-mentioned lack of evidence: it was difficult to interest media professionals in exposing TII based on suspicions rather than clear evidence since this would require an investment of the journalist's time with an unknown return.

\section{Engaging in a national tobacco control coalition}

Tobacco control CSOs often attempted to form national coalitions to join forces and use each other's strengths to maximise advocates' impact. Yet, only in one country, where an alliance had existed for several years, was the national coalition perceived as robust. Elsewhere, coalitions were experienced as fragile, negatively impacting on the strength and scale of activities to counter TII and advance tobacco control.

The capacity of coalition members, in terms of numbers, time and skills, was seen as a key obstacle to a strong coalition-all perceived as determined mainly by financial resources. Almost all CSOs depended on shortterm project-based grants which had limitations:

We cannot afford to have staff permanently. It is just a project that gets approved, then we pool all the resources that we have, to make sure that the project is executed. But it is expensive to operate as an organisation in a country like ours. We need to pay taxes [...] we have bureaucratic expenditures, that never stops. (P21)

Interviewees indicated that funding hindered coalition formation and functionality in two ways. First, scarce opportunities to secure funds led to competition rather than collaboration between CSOs, inhibiting coalition development and longevity. This was also identified as leading to a lack of coordination among CSOs, resulting in duplication of efforts. Second, CSOs were often constrained by their funders' agenda, which often emphasised policy advocacy and implementation rather than addressing TII: 
[funders' name] now concentrates... less on tobacco industry accountability, probably because of their area of focus or their internal issues. For that reason, we had to compromise our staff assigned on industry accountability work. (P17)

In some countries, CSOs reported a lack of flexibility from funders, which could mean that locally identified needs—such as countering TII-could not be addressed as part of the contract:

I have seen organisations which come with ready agreements, and they are not happy to change it, you just sign it or not sign it, right? That's not a true partnership. (P16)

\section{How to enhance activities, overcome challenges and address} unmet needs

\section{Generating and compiling data and evidence}

Advocates identified two main ways through which the data and evidence gaps could be addressed. First, by supporting the development of advocates' skills to generate new data and evidence, contextualise generic data and evidence, and undertake tobacco industry monitoring and investigative research. Webinars or e-learning modules were seen as having a wider reach than on-site training. Yet, the latter could be more impactful since they could be tailored specifically to the context. For virtual or on-site initiatives, advocates highlighted the need for continuous support; "you cannot say I am giving a training once and people will be able to implement all those articles, forget about it." (P12). Reflecting on their experience with courses to date, these were perceived "like a foundation, [but] you need continuous input to strengthen" (P6). Second, most advocates appreciated and used the information on TII available on websites such as Tobacco Tactics but wanted them to include more LMIC-specific data and success stories. Furthermore, an e-learning module could accompany existing resources such as this, guiding advocates on how to use the material.

\section{Accessing policymakers and restricting tobacco industry access}

To gain better access to policymakers, advocates reported they needed to become better at speaking the 'language' of non-health politicians and public officials. This could entail framing tobacco control as a development issue rather than just as a matter of public health. To restrict tobacco industry access to policymakers, participants proposed webinars and other forms of training to increase advocates' understanding of FCTC Article 5.3, as well as that of others such as non-health stakeholders and policymakers. These could be developed in close collaboration with local advocates to ensure they are context-specific and target the appropriate audiences. Lastly, interviewees suggested that the informal ties between policymakers and the tobacco industry, and the conflicts of interest those pose, could be addressed by better exposing these links which, again, could be achieved through investigative skills training for advocates and also journalists.

\section{Working with media}

Advocates stressed the need to raise awareness of and interest in TII among media professionals including editors and journalists and-as noted above-to strengthen their investigative skills through training so they could better expose industry behaviour. The latter could either take the form of webinars targeting journalists directly or written material which LMIC-based advocates can adapt. Advocates also suggested that sharing success stories of advocates working with journalists could inform their approach.

\section{Engaging in a national coalition}

Difficulties around developing robust and sustained tobacco control coalitions were arguably more difficult to address in the short-term, as they reflected broader challenges relating to funding and state capacity and government priorities. Nonetheless, one suggestion was to support advocates in developing coalitions that extend beyond tobacco control, engaging development-oriented CSOs to help frame tobacco control as a development priority. While participants were confident that they could identify, approach and work with crucial coalition supporters, including policy brokers, they suggested management training on coordinating and working more effectively in a coalition.

\section{Overarching needs}

In addition to these focused and pragmatic measures, interviewees consistently pointed to two overarching needs and linked solutions which could facilitate their work in all four areas of activity and improve its impact.

The first was an expressed need for structural change in the way support for LMIC-based tobacco control was funded and coordinated. A move from short-term to longer-term funding to allow more sustainable capacity building, meaning that, for example, capacity built through training would not be lost when funding came to an end. Furthermore, a collaborative rather than competitive approach to funding would encourage coordination among those CSOs working in tobacco control and beyond. Through this, competition and duplication of efforts which lead to inefficiencies could be prevented. Some participants also suggested the possibility of having some additional flexibility in their contracts to more readily counter TII. Lastly, some advocates wanted to be identified more as partners rather than recipients and showed great interest in contributing their knowledge and experience to future capacity-building efforts. This could add to South-South knowledge exchange: "The beauty is that if we stop thinking that I'm here to only benefit the other person. Then you start seeing that there is a lot of scope for mutual learning, right?" (P16).

The second overarching need related to sharing knowledge and learning from each other's experiences; "We don't need to reinvent the wheel because we need to learn from how others handled this situation." (P11). One possible way of meeting this need was establishing or 
strengthening a network linking LMIC-based advocates, where they could exchange information on instances of TII and how to address it and share success stories. Meeting this need would not require as large-scale changes as the other overarching need.

Table3summarisesthekeyfindingsfrom theresultsection.

\section{DISCUSSION}

To our knowledge, this is the first published paper to explore, across a broad group of LMICs, how advocates try to counter TII, and, more specifically the challenges they encounter and how these might be addressed. There was remarkable consistency both within and across countries in the activities advocates engaged in to counter TII, the challenges they faced, their identified needs and, perhaps most importantly, the suggested solutions. As such, this work can be used to directly inform further efforts to address TII.

Our findings indicate that following significant investment in tobacco control advocacy, advocates are working effectively to address TII with their identified activities. The activities are aligned with those outlined in the literature on countering TII in LMICs, ${ }^{16-1927-30}$ HICs $^{31}{ }^{32}$ and supranational settings, ${ }^{33}$ and directly addressing some of the main TII tactics, most notably, producing and disseminating information, seeking direct access to policymakers and using front groups and third parties. ${ }^{9}{ }^{13-15} 34$

Nevertheless, advocates identified significant challenges which centre around the greater power of the tobacco industry. Far more significant information and financial resources are available to the tobacco industry than to CSOs and it has greater ability to access key stakeholders, particularly in powerful non-health ministries. Politicians' links to tobacco companies also enable such access, ${ }^{15}$ and national policies in conflict with public health, for example, listing tobacco as a principal cash crop. ${ }^{35}$ These challenges reflect the concerning implications of corporate power that are not limited to tobacco control, ${ }^{36}$ the taming of which is described as the key political issue of our time'. ${ }^{37}$

The findings suggest some relatively straightforward measures could be taken to advance LMIC-based advocates' capacity to counter TII, and that some structural changes could also be considered.

First, our study highlights that enhancing advocates' skills is a high priority, both research skills as well as skills in monitoring and investigation. Upskilling of advocates in these areas is already being undertaken and funded by international donors. ${ }^{38-40}$ However, in line with previous research, ${ }^{41}$ our findings show the importance of tailoring training initiatives to the particular LMIC's context and moving beyond one-off training to sustain their impact. An initiative that helps to address some of the identified needs is the 'Think Tanks' project delivered by the University of Illinois at Chicago. The project aims to build research capacity into economic and fiscal policies for tobacco control. ${ }^{42}$ It has the potential to nurture local expertise and provide important data that could help counter tobacco industry misinformation.

Second, FCTC Article 5.3 training for non-health stakeholders holds the potential to redress the inequitable access that the tobacco industry has to policymakers compared with CSOs. ${ }^{43}$ As reflected in our research, CSOs sometimes engage in training policy stakeholders and journalists, which is particularly beneficial since they know the context and audience. Thus, advocates would likely benefit from more initiatives that develop skills in designing and delivering such training. In line with previous research, ${ }^{44-46}$ our work also points to potential benefits of framing tobacco control as a development priority and adds that this could be integrated into advocacy to facilitate access to non-health sector stakeholders.

Third, a stronger tobacco control network of LMICbased advocates was perceived as important. While global tobacco control networks exist, our findings suggest having a dedicated network focused on countering TII could be worthwhile.

Addressing the identified issues around funding requires more structural solutions that would not only address advocates' countering efforts but could strengthen tobacco control advocacy in LMICs more generally. In line with the literature on LMIC-based CSOs ${ }^{47-49}$ public health ${ }^{50-52}$ and tobacco control, ${ }^{5354}$ the CSOs represented in this study were typically dependent on international (rather than national) and short-term (rather than long-term) funding, the latter in particular made building lasting capacity and effective coalitions difficult. This concern resonates with the literature on LMIC-based CSOs, suggesting that long-term partnerships between international organisations and local partners build greater capacity among advocates to successfully continue their work after the project ended. ${ }^{475}$ The feasibility of solutions suggested by advocates needs to be carefully unpacked, also considering the implications of having private foundations rather than national governments as key sponsors. ${ }^{48} 49$

As the first study with the explicit aim of exploring advocates' needs in LMICs, its key strength is that it includes the voices from advocates in eight countries (in four WHO regions and from three income-groups). While all countries had recently advanced or attempted to advance experienced recent advances in tobacco control policies, the policies were diverse-from comprehensive to specific policies spanning different aspects of tobacco control.

A limitation is that, as with most qualitative research, ${ }^{56}$ the views expressed are not necessarily generalisable to the wider population of tobacco control advocates. Our participants tended to be experienced and had received training provided by the international tobacco control community, and their views may not necessarily reflect those of advocates without similar opportunities. Yet, many interviewees offered insights into the needs of colleagues rather than solely speaking about their own experience.

An additional limitation is that we only included participants who spoke English. This limited the pool of potential participants, especially given that English 


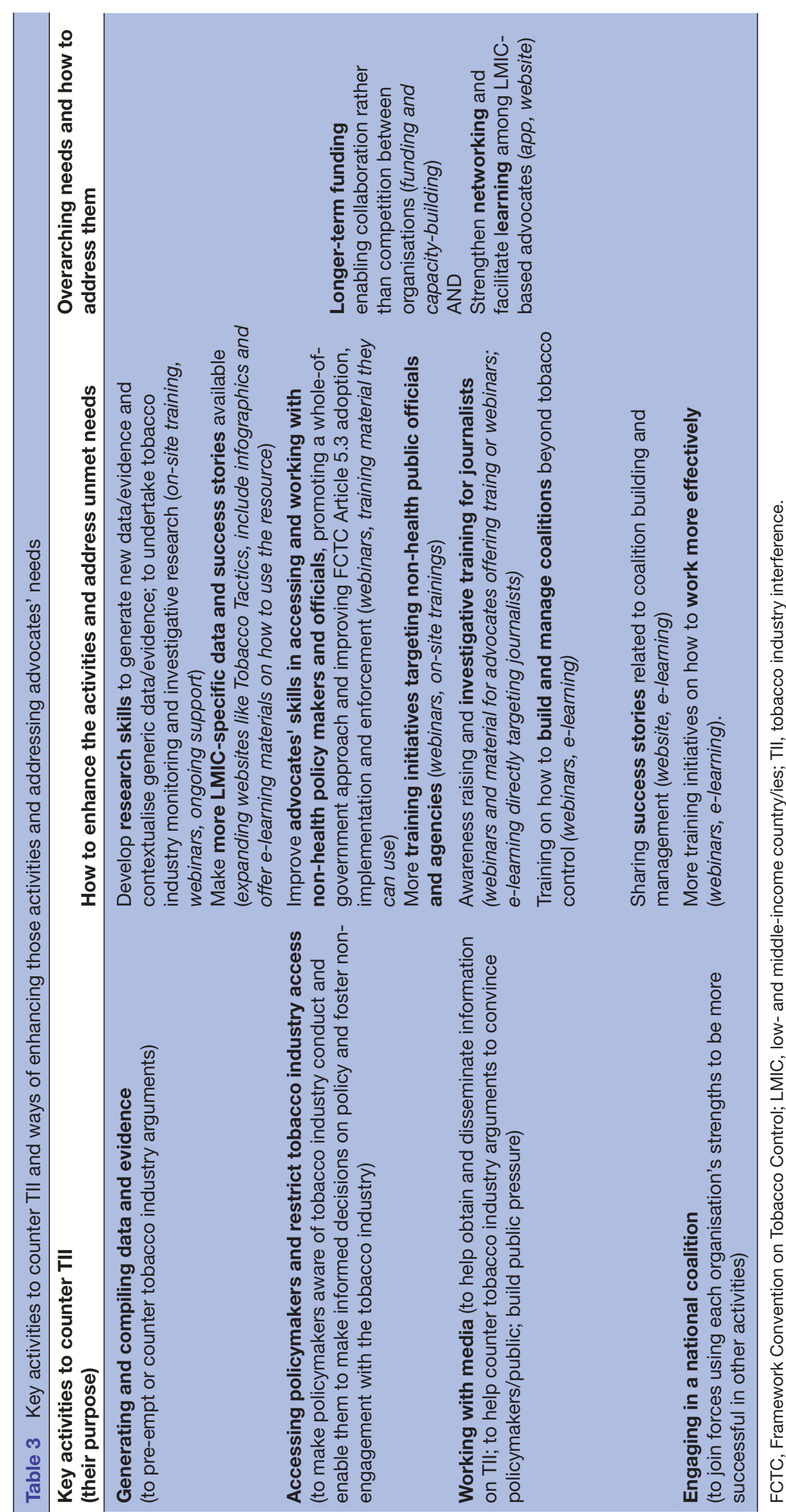


is not the official language in most included countries. A related limitation is that most participants were not native speakers of English which we mitigated by refining the interview schedule following a pilot interview with a non-native speaker of English. If we had not included the English-language requirement, we would have needed support from several interpreters. This would have created additional challenges. ${ }^{24}$

Future research is needed to deepen our understanding of tobacco control advocacy in LMICs and their efforts in countering TII. For example, by studying cases of tobacco control coalitions, one could better understand advocates' efforts in building and sustaining coalitions and compare different approaches. This study also raises important questions about structural changes in the international tobacco control community; the implications and feasibility of possible solutions require further exploration.

\section{CONCLUSION}

To our knowledge, this is the first paper to research LMIC-based advocates' needs in countering TII. Our findings highlight growing confidence in addressing TII among advocates and we identified some tangible and straightforward initiatives that could address unmet needs and enhance advocates' efforts in countering TII. This paper also highlights that more structural changes in how tobacco control is funded and coordinated could strengthen tobacco control in LMICs. Our study is important as LMIC-based advocates may not feel able to advocate for such changes, given the continual pressure to obtain scarce funding from international donors. ${ }^{545758}$

Acknowledgements The authors would like to thank the participants for their time and trust, and Mateusz Zatoński and Emma Green for their comments on drafts of this paper. We would also like to thank the three anonymous reviewers for their constructive feedback.

Contributors $A B G$ gained project funding. $A B G, L R$ and $B K M$ conceptualised the project and designed the interview questionnaire. LR gained ethics approval. BKM and LR collected the data. BKM coded the data and prepared the draft manuscript. $L R$ and $A B G$ provided feedback during manuscript preparation.

Funding We acknowledge the support of Bloomberg Philanthropies' Stopping Tobacco Organizations and Products funding (www.bloomberg.org).

Disclaimer The opinions expressed are those of the authors alone. The funders had no role in study design, data collection, analysis, decision to publish or preparation of the manuscript.

Patient and public involvement Patients and/or the public were not involved in the design, or conduct, or reporting, or dissemination plans of this research.

Patient consent for publication Not required.

Ethics approval Ethical approval for the study was obtained from the University of Bath's Research Ethics Approval Committee for Health (REACH) (Reference: EP 18/19 012), and all participants gave consent to participate.

Provenance and peer review Not commissioned; externally peer reviewed.

Data availability statement № data are available. not applicable.

Open access This is an open access article distributed in accordance with the Creative Commons Attribution Non Commercial (CC BY-NC 4.0) license, which permits others to distribute, remix, adapt, build upon this work non-commercially, and license their derivative works on different terms, provided the original work is properly cited, appropriate credit is given, any changes made indicated, and the use is non-commercial. See: http://creativecommons.org/licenses/by-nc/4.0/.
ORCID iD

Britta Katharina Matthes http://orcid.org/0000-0003-2346-066X

\section{REFERENCES}

1 WHO. WHO Framework Convention on Tobacco Control, 2003. Available: https://www.who.int/tobacco/framework/WHO_FCTC_ english.pdf [Accessed on 23/04/2019].

2 Assunta M. Tobacco industry interference index. ASEAN report on implementation of who framework convention on tobacco control article 5., 2017. Available: https://seatca.org/dmdocuments/TI\% 20 Index\%202017\%209\%20November\%20FINAL.pdf [Accessed on 10/06/2019].

3 FCTC Secretariat. Fact sheets, n.d.. Available: https:// untobaccocontrol.org/kh/article-53/fact-sheets/ [Accessed on 11/12/2019].

4 WHO. Tobacco industry interference: a global brief, 2012. Available: http://www.euro.who.int/_data/assets/pdf_file/0005/165254/ Tobacco-Industry-Interference-A-Global-Brief.pdf [Accessed on 11/12/2019].

5 Campaign for Tobacco-Free Kids. Guide: prepare for tobacco industry interference. Available: https://www.tobaccofreekids.org/ plainpackaging/guides/prepare-for-tobacco-industry-interference [Accessed on 15/12/2019].

6 Anderson CL, Becher H, Winkler V. Tobacco control progress in low and middle income countries in comparison to high income countries. Int J Environ Res Public Health 2016;13:1039.

7 WHO. WHO report on the global tobacco epidemic 2017: monitoring tobacco use and prevention policies 2017. Available: https://apps. who.int/iris/bitstream/handle/10665/255874/9789241512824eng.pdf;jsessionid=BC9F4A66400BA994D9FD21E5E1118204? sequence $=1$ [Accessed on 29/04/2019].

8 Assunta M. Global tobacco industry interference index, 2019. Available: https://exposetobacco.org/wp-content/uploads/2019/10/ GlobalTIIIndex_Report_2019.pdf [Accessed on 22/11/2019].

9 Gilmore AB, Fooks G, Drope J, et al. Exposing and addressing tobacco industry conduct in low-income and middle-income countries. Lancet 2015;385:1029-43.

10 Champagne BM, Sebrié E, Schoj V. The role of organized civil society in tobacco control in Latin America and the Caribbean. Salud Publica Mex 2010;52 Suppl 2:S330-9.

11 Stillman F, Yang G, Figueiredo V, et al. Building capacity for tobacco control research and policy. Tob Control 2006;15 Suppl 1:i18-23.

12 Sturke R, Vorkoper S, Duncan K, et al. Addressing NCDS through research and capacity building in LMICs: lessons learned from tobacco control. Glob Health Action 2016;9:32407.

13 Smith KE, Savell E, Gilmore AB. What is known about tobacco industry efforts to influence tobacco Tax? A systematic review of empirical studies. Tob Control 2013;22:e1.

14 Savell E, Gilmore AB, Fooks G. How does the tobacco industry attempt to influence marketing regulations? A systematic review. PLoS One 2014;9:e87389.

15 Ulucanlar S, Fooks GJ, Gilmore AB. The policy Dystopia model: an interpretive analysis of tobacco industry political activity. PLoS Med 2016;13:e1002125.

16 Charoenca N, Mock J, Kungskulniti N, et al. Success counteracting tobacco company interference in Thailand: an example of FCTC implementation for low- and middle-income countries. Int J Environ Res Public Health 2012;9:1111-34.

17 Crosbie E, Sosa P, Glantz SA. Defending strong tobacco packaging and labelling regulations in Uruguay: transnational tobacco control network versus Philip Morris international. Tob Control 2018;27:185-94.

18 Uang R, Crosbie E, Glantz SA. Tobacco control law implementation in a middle-income country: transnational tobacco control network overcoming tobacco industry opposition in Colombia. Glob Public Health 2018;13:1050-64.

19 Egbe CO, Bialous SA, Glantz S. Role of stakeholders in Nigeria's tobacco control journey after the FCTC: lessons for tobacco control advocacy in low-income and middle-income countries. Tob Control 2019;28:386-93.

20 Green J, Thorogood N. Qualitative methods for health research. London: Sage, 2018.

21 Neergaard MA, Olesen F, Andersen RS, et al. Qualitative description - the poor cousin of health research? BMC Med Res Methodol 2009;9:52.

22 Colorafi KJ, Evans B. Qualitative descriptive methods in health science research. HERD 2016;9:16-25. 
23 Cambridge Dictionary. Advocate. n.d. Available: https://dictionary. cambridge.org/dictionary/english/advocate [Accessed on 01/07/2020].

24 Pitchforth E, van Teijlingen E. International public health research involving interpreters: a case study from Bangladesh. BMC Public Health 2005;5:71.

25 WHO. CSnd. Available: https://www.who.int/social determinants/ themes/civilsociety/en/ [Accessed on 02/02/2020].

26 Pyett PM. Validation of qualitative research in the "real world". Qual Health Res 2003;13:1170-9.

27 Bhatta DN, Bialous S, Crosbie E, et al. Exceeding who framework convention on tobacco control (FCTC) obligations: Nepal overcoming tobacco industry interference to Enact a comprehensive tobacco control policy. Nicotine Tob Res 2019:ntz177.

$28 \mathrm{Tam}$ J, van Walbeek C. Tobacco control in Namibia: the importance of government capacity, media coverage and industry interference. Tob Control 2014;23:518-23.

29 Egbe CO, Bialous SA, Glantz SA. Avoiding "A Massive Spin-Off Effect in West Africa and Beyond": The Tobacco Industry Stymies Tobacco Control in Nigeria. Nicotine Tob Res 2017;19:877-87.

30 Madrazo-Lajous A, Guerrero-Alcántara A. Undue tobacco industry interference in tobacco control policies in Mexico. Salud Publica Mex 2012:54:315-22.

31 Tsoukalas T, Glantz SA. The Duluth clean indoor air ordinance: problems and success in fighting the tobacco industry at the local level in the 21st century. Am J Public Health 2003;93:1214-21.

32 Arnott D, Dockrell M, Sandford A, et al. Comprehensive smoke-free legislation in England: how advocacy won the day. Tob Control 2007:16:423-8.

33 Weishaar H, Amos A, Collin J. Best of enemies: using social network analysis to explore a policy network in European smoke-free policy. Soc Sci Med 2015;133:85-92.

34 Lee S, Ling PM, Glantz SA. The vector of the tobacco epidemic: tobacco industry practices in low and middle-income countries. Cancer Causes Control 2012;23 Suppl 1:117-29.

35 Hu T-wei, Lee AH. Tobacco control and tobacco farming in African countries. J Public Health Policy 2015;36:41-51.

36 Wiist WH, ed. The bottom line or public health: tactics corporations use to influence health and health policy, and what we can do to counter them. Oxford University Press: Oxford, 2010

37 Monbiot G. Taming corporate power: the key political issue of our age 2014. Available: https://www.theguardian.com/commentisfree/ 2014/dec/08/taming-corporate-power-key-political-issue-alternative [Accessed on 10/02/2020].

38 Institute for Global Tobacco Control. Global tobacco control: learning from the experts, 2020. Available: https://globaltobaccocontrol. org/content/global-tobacco-control-learning-experts [Accessed on 06/02/2020]

39 ATCA. About us - What we do, 2020. Available: https://atca-africa. org/en/about-us/what-we-do [Accessed on 21/02/2020].

40 Tobacco Tactics. Tobacco Control Research Group: TIMRA Model, 2018. Available: https://tobaccotactics.org/wiki/tobacco-controlresearch-group-timra-model/ [Accessed on 22/02/2020].

41 Shilton T, Champagne B, Blanchard C, et al. Towards a global framework for capacity building for non-communicable disease advocacy in low- and middle-income countries. Glob Health Promot 2013;20:6-19.

42 University of Illinois at Chicago. Think tanks project: accelerating progress on tobacco taxes in Low- and Middle-Income countries, 2020. Available: https://tobacconomics.org/projects/bloomberginitiative-accelerating-progress-on-tobacco-taxes-in-low-andmiddle-income-countries/ [Accessed on 07/01/2020].
43 Crosbie E, Sebrié EM, Glantz SA. Tobacco industry success in Costa Rica: the importance of FCTC article 5.3. Salud Publica Mex 2012;54:28-38

44 Reddy KS, Yadav A, Arora M, et al. Integrating tobacco control into health and development agendas. Tob Control 2012;21:281-6.

45 Kulik MC, Bialous SA, Munthali S, et al. Tobacco growing and the sustainable development goals, Malawi. Bull World Health Organ 2017;95:362-7.

46 Matthes B, Zatoński M. Tobacco control and sustainable development: shared challenges and future opportunities. Journal of Health Inequalities 2019;5:71-9.

47 AbouAssi K. Hands in the pockets of mercurial donors: NGO response to shifting funding priorities. Nonprofit Volunt Sect $Q$ 2013;42:584-602.

48 Moran M, Stone D. The New Philanthropy: Private Power in International Development Policy? In: Grugel J, Hammett D, eds. The Palgrave Handbook of international development. London: Palgrave Macmillan, 2016: 297-313.

49 Clarke G. The new global governors: globalization, civil society, and the rise of private philanthropic foundations. Journal of Civil Society 2019:15:197-213.

50 The Lancet. Who runs global health? Lancet 2009;373:(9681):2083.

51 McCoy D, Chand S, Sridhar D. Global health funding: how much, where it comes from and where it goes. Health Policy Plan 2009;24:407-17.

52 Murray CJL, Anderson B, Burstein R, et al. Development assistance for health: trends and prospects. Lancet 2011;378:8-10.

53 Stoklosa M, Ross $\mathrm{H}$. Tobacco control funding for low-income and middle-income countries in a time of economic hardship. Tob Control 2014;23:e122-6.

54 Callard C. Follow the money: how the billions of dollars that flow from smokers in poor nations to companies in rich nations greatly exceed funding for global tobacco control and what might be done about it. Tob Control 2010;19:285-90.

55 Ismail Z. Advantages and Value of Funding NGOs in the Global South. K4D Helpdesk Report 2019. Available: https://opendocs.ids. ac.uk/opendocs/bitstream/handle/20.500.12413/14392/539 Direct Funding_for_NGOs_in_the_South.pdf?sequence $=1$ \&isAllowed $=y$ [Accessed on 22/06/2020].

56 Carminati L. Generalizability in qualitative research: a tale of two traditions. Qual Health Res 2018;28:2094-101.

57 Smith J, Buse K, Gordon C. Civil society: the catalyst for ensuring health in the age of sustainable development. Global Health 2016;12:40.

58 Framework Convention Alliance. 2018 annual report, 2018. Available: https://www.fctc.org/wp-content/uploads/2019/03/FCA-AnnualReport-2018.pdf [Accessed on 10/01/2020].

59 WHO. Alphabetical list of who member states. n.d.. Available: https:// www.who.int/choice/demography/by_country/en/ [Accessed on 23/12/2019].

60 World Bank. World bank country and lending groups, n.d.. Available: https://datahelpdesk.worldbank.org/knowledgebase/articles/ 906519-world-bank-country-and-lending-groups [Accessed on 02/01/2020].

61 Campaign for Tobacco-Free Kids. Tobacco control laws: legislation. n.d. Available: https://www.tobaccocontrollaws.org/legislation [Accessed on 22/12/2019].

62 World Bank. Taxing tobacco: a win-win for public health outcomes and mobilizing domestic resources, 2018. Available: https://www. worldbank.org/en/topic/tobacco/brief/taxing-tobacco-a-win-win-forpublic-health-outcomes-mobilizing-domestic-resources [Accessed on $20 / 12 / 2019]$. 